Article

\title{
Sustainable Mobility: Using a Global Energy Model to Inform Vehicle Technology Choices in a Decarbonized Economy
}

\author{
Maria Grahn $^{1, *}$, Erica Klampfl ${ }^{2}$, Margaret Whalen ${ }^{2}$ and Timothy J. Wallington ${ }^{2}$ \\ 1 Department of Energy and Environment, Physical Resource Theory, \\ Chalmers University of Technology, Göteborg 41296, Sweden \\ 2 Systems Analytics and Environmental Sciences Department, Ford Motor Company, \\ Mail Drop RIC-2122, Dearborn, MI 48121, USA; E-Mails: eklampfl@ford.com (E.K.); \\ mwhalen@ford.com (M.W.); twalling@ford.com (T.W.) \\ * Author to whom correspondence should be addressed; E-Mail: maria.grahn@chalmers.se; \\ Tel.: +46-31-772-3104; Fax: +46-31-772-1152.
}

Received: 25 March 2013; in revised form: 11 April 2013 / Accepted: 15 April 2013 /

Published: 29 April 2013

\begin{abstract}
The reduction of $\mathrm{CO}_{2}$ emissions associated with vehicle use is an important element of a global transition to sustainable mobility and is a major long-term challenge for society. Vehicle and fuel technologies are part of a global energy system, and assessing the impact of the availability of clean energy technologies and advanced vehicle technologies on sustainable mobility is a complex task. The global energy transition (GET) model accounts for interactions between the different energy sectors, and we illustrate its use to inform vehicle technology choices in a decarbonizing economy. The aim of this study is to assess how uncertainties in future vehicle technology cost, as well as how developments in other energy sectors, affect cost-effective fuel and vehicle technology choices. Given the uncertainties in future costs and efficiencies for light-duty vehicle and fuel technologies, there is no clear fuel/vehicle technology winner that can be discerned at the present time. We conclude that a portfolio approach with research and development of multiple fuel and vehicle technology pathways is the best way forward to achieve the desired result of affordable and sustainable personal mobility. The practical ramifications of this analysis are illustrated in the portfolio approach to providing sustainable mobility adopted by the Ford Motor Company.
\end{abstract}

Keywords: global energy scenarios; carbon emissions; vehicle technologies; fuel choices 


\section{Introduction}

Global climate change, caused by increasing levels of greenhouse gases (GHG) in the Earth's atmosphere resulting from human activities [1] is a major issue of current concern. $\mathrm{CO}_{2}$ released during fossil fuel combustion and deforestation is the largest contributor to radiative forcing of the climate system [1]. The United Nations Framework Convention on Climate Change has been ratified by 192 countries and calls for stabilization of greenhouse gas concentrations in the atmosphere at a level that would "prevent dangerous anthropogenic interference with the climate system" [2]. There is no consensus on a precise level of $\mathrm{CO}_{2}$ in the atmosphere that would prevent such interference, but Rogelj et al. [3] show that the two degree target can be met with at least fifty-fifty chance if the $\mathrm{CO}_{2}$-eq emissions is halved by 2050 and reduced by $75 \%$ by 2100 compared to year 2000 . In this study we follow $\mathrm{CO}_{2}$ reduction curves presented by Wigley et al. [4] consistent with stabilization of $\mathrm{CO}_{2}$ concentration in the Earth's atmosphere at various levels, mainly focusing on 450 parts per million (ppm). Since the curve towards $450 \mathrm{ppm}$ has a similar relative reduction in $\mathrm{CO}_{2}$ emissions as the $\mathrm{CO}_{2}$-eq emissions presented by Rogelj et al. [3], we assume that these $\mathrm{CO}_{2}$ emissions are broadly in line with those having an approximately $50 \%$ chance of meeting the two degree target.

Efforts to stabilize atmospheric $\mathrm{CO}_{2}$ levels are complicated by many considerations, not least of which being the fact that $\mathrm{CO}_{2}$ emissions are spread across different geographic regions and economic sectors (e.g., industrial, residential, commercial, transportation). Figure 1 shows the regional distribution of fossil fuel $\mathrm{CO}_{2}$ emissions in 2009.

Figure 1. Distribution of fossil fuel $\mathrm{CO}_{2}$ emissions (totals may not sum to $100 \%$ due to rounding).

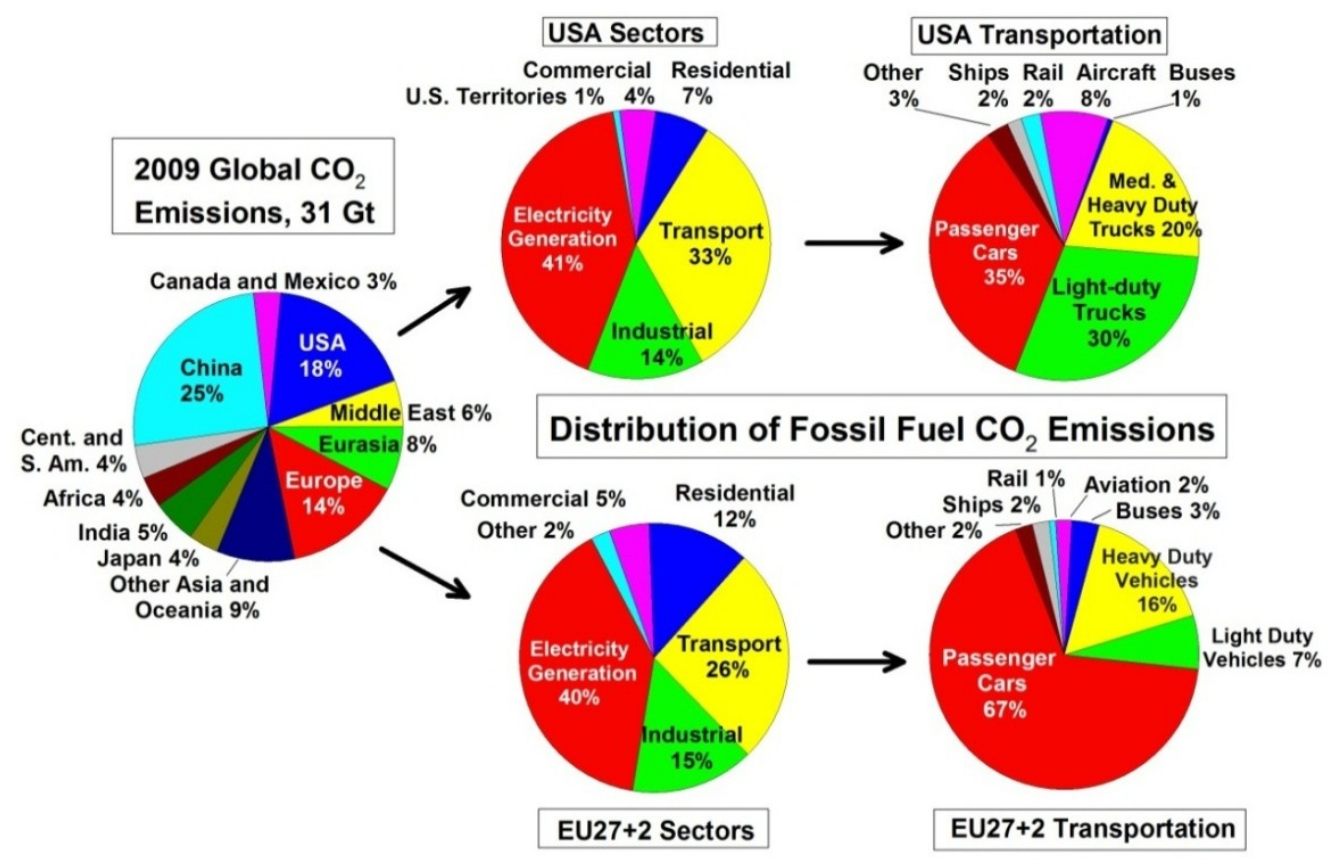

The pie charts on the top of Figure 1 show (from left to right) a breakdown of U.S. emissions into end-use sectors (e.g., commercial, residential, and transport) and a breakdown of emissions from the U.S. transportation sector into different transportation modes (e.g., light-duty trucks, passenger cars, and aircraft). The pie charts on the bottom of Figure 1 show comparable data for the 29 European 
countries (the EU-27 countries: Austria, Belgium, Bulgaria, Cyprus, Czech Republic, Denmark, Estonia, Finland, France, Germany, Greece, Hungary, Ireland, Italy, Latvia, Lithuania, Luxembourg, Malta, Netherlands, Poland, Portugal, Romania, Slovenia, Slovakia, Spain, Sweden, and United Kingdom; plus Norway and Switzerland). Data for these charts were obtained from the U.S. Environmental Protection Agency, the U.S. Energy Information Agency, the European Environment Agency, and TREMOVE 3.3.2 as described elsewhere [5]. As evident from Figure 1, passenger vehicles (cars and light-duty trucks) in the USA and EU-29 are responsible for approximately $65 \% \times 33 \% \times 18 \%=4 \%$ and $74 \% \times 26 \% \times 14 \%=3 \%$ of global fossil fuel $\mathrm{CO}_{2}$ emissions, respectively. On a global basis, in 2009 light-duty vehicles were responsible for approximately 3.1 gigatonnes $\mathrm{CO}_{2}\left(10^{9}\right.$ tonnes, Gt) (estimated from the World Business Council for Sustainable Development's Sustainable Mobility Project (SMP) model [6]), which represents about 10\% of the approximately $31 \mathrm{Gt}$ of global fossil fuel and cement $\mathrm{CO}_{2}$ emissions [7].

The complete elimination of all emissions from light-duty vehicles would result in an approximately $10 \%$ reduction in global emissions, which is less than one third of the reduction needed by 2050 to follow an emissions pathway consistent with stabilization at $450 \mathrm{ppm}$. Stabilization of $\mathrm{CO}_{2}$ at $450 \mathrm{ppm}$ will require actions in many geographic regions and many different economic sectors, which raises the question of how to distribute the task amongst the sectors and regions. Focusing on the sector issue, there are in principle two approaches: all economic sectors face the same percentage reduction, or putting all sectors under the same cap and then letting the market find the lowest cost solution. The first approach is conceptually the simplest, but is more expensive as it ignores differences in carbon mitigation costs in different sectors. The second is economically more efficient and may, in fact, be easier to implement as an overall carbon tax or cap-and-trade system does not distinguish between sectors nor is sector specific control needed.

To provide a tool for decision makers, we developed a global energy model (GET-RC 6.1) that includes a detailed description of passenger vehicle technology options [5,8-13] (Details of the scientific studies behind the mathematical representation of the global energy transition (GET) model are provided by Azar et al. [8-10]). It is important to understand the fuel and vehicle technology choices available for passenger vehicles and how these might fit into the larger global energy system. For example, it is important to understand how the availability of carbon capture and storage (CCS) and low- $\mathrm{CO}_{2}$ electricity from renewable sources such as concentrating solar power (CSP) may influence the cost-effective fuel and vehicle technology choices in a future carbon constrained world. There have been few global long-term energy systems studies that include detailed descriptions of the range of available light-duty vehicle technologies [14-20]. The development of a robust business strategy consistent with climate protection provides guidance for long-term product development decisions and can provide a competitive advantage for a global automobile manufacturer.

The vehicle technology cost cases presented here build upon and extend the existing body of published analyses from the GET-RC 6.1 model [5,11-13]. Specifically, we consider here a much wider range of hydrogen storage costs and fuel cell stack costs than in our previous work. Based on U.S. Department of Energy targets [21,22], we have extended the range of storage costs from $\$ 1,500 / \mathrm{GJ}$ down to $\$ 500 / \mathrm{GJ}$ and fuel cell stack costs from $\$ 65 / \mathrm{kW}$ down to $\$ 45 / \mathrm{kW}$ in the model. The aim of this study is to assess how uncertainties in future vehicle technology costs affect technology adoption and to what extent developments in other energy sector affects the cost-effective fuel and 
technology choices for light-duty vehicle options. We illustrate the utility of the GET-RC 6.1 model in informing vehicle technology decisions.

\section{Model Description}

The linear programming (LP) GET model constructed by Azar, Lindgren, and co-workers [8-10] covers the global energy system and is designed to meet exogenously-given energy demand levels, subject to a $\mathrm{CO}_{2}$ constraint, at the lowest system cost (all costs are in US\$). Figure 2 shows a graphic depicting the main features in the model. The mathematical description of the model is given in the Supporting Information. In this section, we discuss assumptions and limitations of the GET model around the structure, energy demand, primary energy sources, emission factors, cost data, constraints, and personal transportation.

Figure 2. The basic flow chart of supply and fuel choices in GET-RC 6.1. Labels used: hydrogen (H2), electricity (ELEC), low and high temperature heat for the residential, service, agricultural, and industrial sectors (HEAT), natural gas as transportation fuel (NG FOR TRSP), diesel and gasoline (PETRO) and synthetic fuels for aviation (AIR FUEL). Note that electricity and hydrogen can loop back to the energy conversions module allowing electricity to generate heat and/or hydrogen and allowing hydrogen to generate electricity and/or heat.

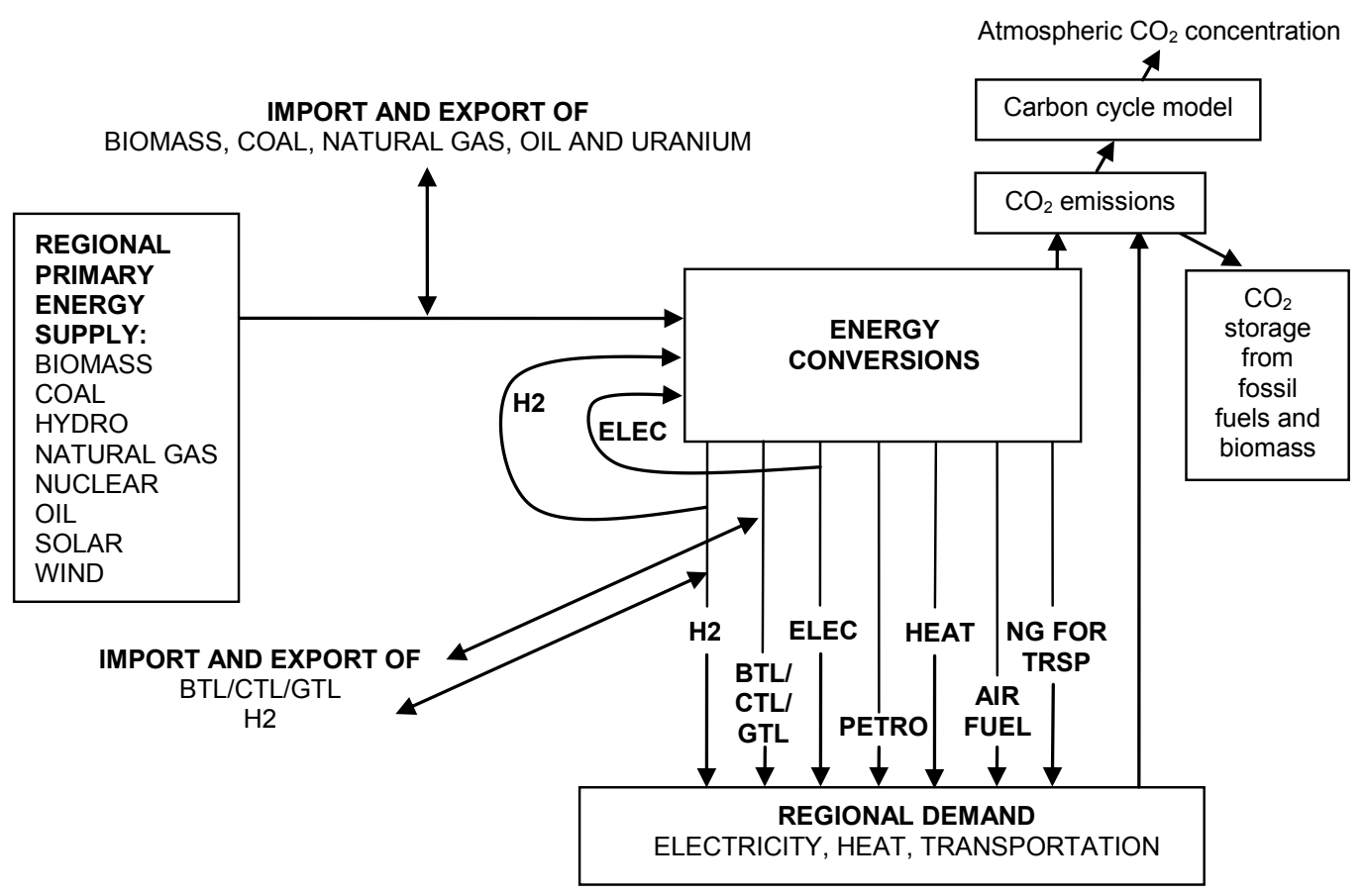

\subsection{Model Structure}

In the model, the world is treated as ten distinct regions with unimpeded movement of energy resources between regions (with the exception of electricity) with costs ascribed to such movement. We aggregate regional solutions to supply global results and constrain global $\mathrm{CO}_{2}$ emissions to be consistent with stabilization of atmospheric $\mathrm{CO}_{2}$ concentration at 450 or $550 \mathrm{ppm}$ [4]. The model does 
not consider greenhouse gases other than $\mathrm{CO}_{2}$. The model time period is 1990-2140 with 10-year time steps: we present and discuss the results for time period 2010-2100.

The description of the energy system in the model is a simplification of reality in at least five important respects: (i) consideration of limited number of technologies; (ii) assumption of price-inelastic demand; (iii) selections made only on the basis of cost; (iv) "perfect foresight" with no uncertainty of future costs, climate targets, or energy demand; and (v) no consideration of the importance of energy security, local air quality, or other benefits of new technologies. The model does not predict the future and is not designed to forecast the future development of the energy system. Nevertheless, the model is a useful tool to understand the system behavior and the interactions and connections between energy technology options in different sectors in a future carbon-constrained world.

\subsection{Energy Demand}

Energy demand is divided into three sectors: (i) electricity; (ii) transportation; and (iii) "heat". Heat comprises all stationary uses of energy except for those associated with generating electricity or transportation fuels. The current study emphasizes personal transportation in light-duty vehicles. Regional energy demand in the model is derived by combining World Energy Council projections of global population (increasing to 10 billion in 2050 and 11.7 billion in 2100) and estimates of the development of per capita income (IIASA/WEC scenario C1) [23], as well as assumptions regarding the activity demand (e.g., person-km, pkm, for personal transportation) associated with a given per capita income. For more details regarding the derivation of regional energy demand see Azar et al. [8].

\subsection{Primary Energy Sources and Emission Factors}

Biomass raw material cost was assumed to be $\$ 4 / \mathrm{GJ}$ in Europe and the Former Soviet Union, $\$ 3 / \mathrm{GJ}$ in North America, Australia, and Japan, and \$2/GJ in all other areas. We have chosen to follow the regional biomass supply potentials described in Johansson et al. [24] adding up to a global potential of $205 \mathrm{EJ} / \mathrm{y}$. This potential is similar to an estimation by the Organization for Economic Cooperation and Development of 245 EJ [25]. Hoogwijk [26] also presents a similar biomass supply potential. For four different scenarios and two biomass production cost levels (lower than $\$ 2 / \mathrm{GJ}$ and lower than $\$ 4 / \mathrm{GJ}$ ), Hoogwijk [27] estimated the global supply potential to lie in the range of 130-439 EJ/y (with a mean value of $253 \mathrm{EJ} / \mathrm{y}$ ) by the year 2050. The GET-RC 6.1 model includes global ultimately recoverable resources of oil, gas, and coal of approximately 12,000 EJ (2 trillion barrels), 11,000 EJ (300 trillion $\left.\mathrm{m}^{3}\right)$, and 265,000 EJ (10 trillion tonnes hard coal), respectively. To account for reserve growth, the supply potentials for oil and natural gas are approximately $50 \%$ higher than current estimates of economically-recoverable, conventional reserves [27]. We use the following $\mathrm{CO}_{2}$ emission factors: natural gas: 15.4, oil: 20.5 , and coal: $24.7 \mathrm{kgC} / \mathrm{GJ}$ [28]. We assume that future use of nuclear, hydro, wind, biomass, and solar energy contribute negligible $\mathrm{CO}_{2}$ emissions.

\subsection{Cost and Performance Data}

Data for vehicle technology, as well as conversion plants and infrastructure (e.g., investment costs, conversion efficiencies, lifetimes, and capacity factors) are held constant at their "mature levels": for 
details see the supporting information in Grahn et al. [12] and Wallington et al. [13]. We assume mature technology costs throughout the time period considered. The model was tested to confirm that this assumption did not lead to an unduly rapid adoption of technologies. We further assume that all technologies are available in all regions. All prices and costs are in real terms as future inflation is not considered. A global discount rate of 5\% per year was used for the net present value calculations. There are significant uncertainties inherent in estimating future technology costs, and the cost assumptions continue to be revised as further information becomes available.

\subsection{Constraints}

Constraints on how rapidly changes can be made in the energy system have been added to the model to avoid solutions that are obviously unrealistic. This includes constraints on the maximum expansion rates of new technologies (in general, the constraints are set so that it takes 50 years to change the entire energy system), as well as annual or total extraction limits on the different available energy sources.

The contribution of intermittent electricity sources (wind and solar photovoltaic) is limited to a maximum of $30 \%$ of the electricity use. Concentrated solar power (CSP) is considered non-intermittent [12] and available for all regions except Former Soviet Union (which is a region without access to sufficient direct solar insolation). To simulate the actual situation in developing countries, a minimum of $30 \mathrm{EJ} / \mathrm{y}$ of the heat demand is required from biomass during the first decades. For carbon capture and storage (CCS), we assumed a storage capacity of $600 \mathrm{GtC}$ [29], a maximum rate of increase of $\mathrm{CCS}$ of $100 \mathrm{MtC} / \mathrm{y}$ and negligible leakage of stored $\mathrm{CO}_{2}$. The future role of nuclear energy is primarily a political decision and will depend on several issues such as safety, waste disposal, questions of nuclear weapons proliferation and public acceptance. We assume that the contribution of nuclear power does not exceed current levels. The cost and $\mathrm{CO}_{2}$ attributes of CSP assumed in the model are similar to those of nuclear power and hence CSP serves to some degree as a proxy for additional nuclear power.

\subsection{Personal Transportation}

Gasoline and diesel fuels are not differentiated but collectively described as petroleum (petro). We consider five fuel options: petro, natural gas (NG), synthetic fuels (coal to liquid, CTL; gas to liquid, GTL; biomass to liquid, BTL), electricity, and hydrogen $\left(\mathrm{H}_{2}\right)$. We also take into account five vehicle technologies: internal combustion engine vehicles (ICEVs), hybrid electric vehicles (HEVs), plug-in hybrid electric vehicles (PHEVs), battery electric vehicles (BEVs), and fuel cell vehicles (FCVs).

The relative efficiency values used in the model were derived from published studies as discussed elsewhere $[12,13]$. For consistency and simplicity, we assume the relative efficiency of PHEVs when powered by electricity is the same as BEVs. In the model, each PHEV energy fraction is handled separately. An all-electric battery range of $65 \mathrm{~km}$ was adopted for PHEVs, which enables approximately two-thirds of their daily driving distance to be powered by electricity from the grid on a single overnight charge. HEVs have a relatively short all-electric range (we assume $2 \mathrm{~km}$ ). The all-electric range was set to $200 \mathrm{~km}$ for BEVs. Results from cases in which a range of $100 \mathrm{~km}$ was 
assumed for BEVs are presented elsewhere [30]. Powertrain types and efficiencies for freight trucks were updated to be consistent with those assumed in the car sector.

Table 1 provides the incremental cost data relative to internal combustion engine vehicles powered by petroleum (Petro ICEV) for the twelve vehicle technology cases considered in the present work [12,13]. These incremental costs are estimated for the technologies in their "mature" state. We have estimated the incremental vehicle costs from the battery, hydrogen storage, natural gas storage, and fuel cell stack component costs. This approach ensures internal consistency between the cost assumptions for competing vehicle technologies (e.g., that we have the same battery cost assumption in all vehicles in a given scenario). Fuel storage is a significant component of vehicle cost for vehicles running on natural gas, hydrogen, and batteries. As vehicle fuel consumption is assumed to steadily decline over the study period for all vehicle types (reflecting, for example, aerodynamic and weight actions), energy storage requirements for the assumed 500-km range also decline proportionally. To estimate vehicle costs in GET-RC 6.1, we assume energy storage costs consistent with fuel consumption for each vehicle type in the year 2050, assuming a globally-averaged vehicle size (consistent with $2.45 \mathrm{MJ} / \mathrm{km}$ for Petro ICEVs). Model runs assessed the sensitivity to variation of the following: battery costs from $\$ 150 / \mathrm{kWh}$ (goal for long-term commercialization set by the U.S. Advanced Battery Consortium [31]) to $\$ 450 / \mathrm{kWh}$ (above which the model results were insensitive to battery cost); hydrogen storage costs from $\$ 500 /$ GJ (US Department of Energy target for 2015) to $\$ 4,500 / \mathrm{GJ}$ (above which the model results were insensitive to hydrogen storage cost and comparable to current estimates [22]); and fuel cell stack cost from $\$ 45 / \mathrm{kW}$ to $\$ 125 / \mathrm{kW}$.

Table 1. Cases for incremental costs of different passenger vehicle technology and fuel options relative to conventional petroleum internal combustion engine technology explored in current work.

\begin{tabular}{|c|c|c|c|c|c|c|c|c|c|c|c|c|}
\hline $\begin{array}{c}\text { Vehicle } \\
\text { Technology }\end{array}$ & $\begin{array}{c}\text { Case } \\
\# 1^{a}\end{array}$ & $\begin{array}{c}\text { Case } \\
\# 2\end{array}$ & $\begin{array}{c}\text { Case } \\
\# 3\end{array}$ & $\begin{array}{c}\text { Case } \\
\# 4^{a}\end{array}$ & $\begin{array}{c}\text { Case } \\
\# 5^{a}\end{array}$ & $\begin{array}{c}\text { Case } \\
\# 6^{\mathrm{a}}\end{array}$ & $\begin{array}{c}\text { Case } \\
\# 7\end{array}$ & $\begin{array}{c}\text { Case } \\
\# 8\end{array}$ & $\begin{array}{c}\text { Case } \\
\# 9\end{array}$ & $\begin{array}{c}\text { Case } \\
\# 10\end{array}$ & $\begin{array}{c}\text { Case } \\
\# 11\end{array}$ & $\begin{array}{c}\text { Case } \\
\# 12\end{array}$ \\
\hline $\begin{array}{c}\text { H2 storage } \\
(\$ / G J)\end{array}$ & 2,500 & 500 & 1,000 & 1,500 & 2,500 & 3,500 & 4,500 & 2,500 & 2,500 & 2,500 & 1,500 & 1,500 \\
\hline $\begin{array}{c}\text { FC Stack } \\
(\$ / \mathrm{kW})\end{array}$ & 65 & 95 & 95 & 95 & 95 & 95 & 95 & 45 & 95 & 125 & 95 & 95 \\
\hline $\begin{array}{l}\text { Battery } \\
(\$ / k W h)\end{array}$ & 300 & 300 & 300 & 300 & 300 & 300 & 300 & 300 & 300 & 300 & 150 & 450 \\
\hline Petro ICEV & 0 & 0 & 0 & 0 & 0 & 0 & 0 & 0 & 0 & 0 & 0 & 0 \\
\hline Synth ICEV & 100 & 100 & 100 & 100 & 100 & 100 & 100 & 100 & 100 & 100 & 100 & 100 \\
\hline NG ICEV & 1,400 & 1,400 & 1,400 & 1,400 & 1,400 & 1,400 & 1,400 & 1,400 & 1,400 & 1,400 & 1,400 & 1,400 \\
\hline H2 ICEV & 2,500 & 400 & 1,000 & 1,500 & 2,500 & 3,500 & 4,700 & 2,500 & 2,500 & 2,500 & 1,500 & 1,500 \\
\hline Petro HEV & 1,600 & 1,600 & 1,600 & 1,600 & 1,600 & 1,600 & 1,600 & 1,600 & 1,600 & 1,600 & 1,300 & 1,900 \\
\hline Synth HEV & 1,700 & 1,700 & 1,700 & 1,700 & 1,700 & 1,700 & 1,700 & 1,700 & 1,700 & 1,700 & 1,400 & 2,000 \\
\hline $\mathrm{BEV}$ & 15,500 & 15,500 & 15,500 & 15,500 & 15,500 & 15,500 & 15,500 & 15,500 & 15,500 & 15,500 & 7,900 & 23,300 \\
\hline Petro PHEV & 5,500 & 5,500 & 5,500 & 5,500 & 5,500 & 5,500 & 5,500 & 5,500 & 5,500 & 5,500 & 3,000 & 8,000 \\
\hline Synth PHEV & 5,600 & 5,600 & 5,600 & 5,600 & 5,600 & 5,600 & 5,600 & 5,600 & 5,600 & 5,600 & 3,100 & 8,100 \\
\hline Petro FCV & 4,500 & 6,000 & 6,000 & 6,000 & 6,000 & 6,000 & 6,000 & 3,500 & 6,000 & 7,500 & 5,700 & 6,300 \\
\hline Synth FCV & 4,500 & 6,000 & 6,000 & 6,000 & 6,000 & 6,000 & 6,000 & 3,500 & 6,000 & 7,500 & 5,700 & 6,300 \\
\hline $\mathrm{H} 2 \mathrm{FCV}$ & 4,900 & 5,000 & 5,400 & 5,700 & 6,400 & 7,000 & 7,700 & 3,900 & 6,400 & 7,900 & 5,400 & 6,000 \\
\hline
\end{tabular}


The data in Table 1 are based on literature estimates of potential mature technology costs that we equate to costs in 2030-2050 [12,13]. It is unclear whether these costs will be realized in the future. The technology costs were assumed to remain constant during the entire time period modeled. While it is clearly not appropriate to use mature costs for advanced technology during the beginning of the time period, this assumption did not compromise the study because advanced technologies are not initially required to meet the $\mathrm{CO}_{2}$ constraints, and so were not selected by the model in the beginning of the time period. The base passenger vehicle with a conventional, internal-combustion engine powered by petroleum is set to $\$ 20,000$. The incremental cost for a comparable vehicle powered instead by synthetic fuel (e.g., biofuel) is set to $\$ 100$ for component modifications required to make the vehicle compatible with such fuels. For consistency the incremental costs for other synthetic-fuel vehicles were increased by $\$ 100$ relative to the comparable petroleum-powered vehicle. Costs for alternative powertrain and alternative fuel technology in freight trucks were updated to be consistent with those assumed in the car sector.

\section{Results}

The GET-RC 6.1 model has been developed to investigate cost-effective fuel and vehicle technology options for passenger vehicles consistent with stabilization of atmospheric $\mathrm{CO}_{2}$. We have investigated the sensitivity of the results to seven different input parameters: $\mathrm{CO}_{2}$ stabilization target concentration (ppm), battery cost $(\$ / \mathrm{kWh}), \mathrm{H}_{2}$ storage cost $(\$ / \mathrm{GJ})$, fuel cell stack cost $(\$ / \mathrm{kW})$, natural gas storage cost $(\$ / \mathrm{GJ})$, availability of carbon capture and storage (CCS), and availability of concentrating solar power. We have considered five $\mathrm{CO}_{2}$ stabilization targets $(400,450,500,550 \mathrm{ppm}$, or no $\mathrm{CO}_{2}$ constraint), three battery costs $(\$ 150, \$ 300$, or $\$ 450 / \mathrm{kWh})$, six $\mathrm{H}_{2}$ storage costs $(\$ 500, \$ 1,000$, $\$ 1,500, \$ 2,500, \$ 3,500$, or $\$ 4,500 / \mathrm{GJ})$, four fuel cell stack costs $(\$ 45, \$ 65, \$ 95$, or $\$ 125 / \mathrm{kW})$, three natural gas storage costs $(\$ 1,000, \$ 1,150$, or $\$ 1,300 / \mathrm{GJ})$, carbon capture and storage (CCS) available or not, and concentrating solar power available or not for a total of $5 \times 3 \times 6 \times 4 \times 3 \times 2 \times 2=4,320$ possible scenarios. Clearly, it is not possible to provide the results from all possible scenarios and instead we present here the results from representative scenarios that illustrate the important conclusions from the model. The twelve vehicle cost cases discussed here demonstrate the impact of different hydrogen storage, fuel cell stack, and battery costs on the lowest cost fuel-vehicle choices in a carbon constrained world.

Table 1 contains the cost values for the twelve cases. Case \#1 assumes a hydrogen storage cost of $\$ 2,500 / \mathrm{GJ}$, a fuel cell stack cost of $\$ 65 / \mathrm{kW}$, and a battery cost of $\$ 300 / \mathrm{kWh}$. Cases $\# 2-7$ explore the impact of hydrogen storage cost over the range \$500-4,500/GJ. Cases \#8-10 explore the impact of fuel cell stack costs over the range $\$ 45-125 / \mathrm{kW}$. Finally, cases \#10-12 explore the impact of battery costs over the range $\$ 150-450 / \mathrm{kWh}$. All cases discussed here assume a NG-ICEV storage cost of \$1,150/GJ. The incremental costs given in Table 1 are estimated for the technologies in their "mature" state.

As described in Section 2, the GET-RC6.1 model includes energy use in all sectors and in all regions. It is impractical to present the results for energy use in all sectors from the different cases. Our focus is on understanding the system dynamics that may influence the choice of light-duty vehicle and fuel technologies in a future carbon-constrained world. We present the aggregate global light-duty vehicle choices and the global primary energy supply results. However, we note that in addition to the 
results that we will present below, the model is optimizing (for lowest global system cost) the choice of technologies used in all other transportation modes (air, road, rail, sea) for both passengers and freight, in electricity production, and heat generation (selecting from the different available primary energy sources).

Figures 3-6 contain results from the different model runs. The results shown are the lowest cost solution to meet a given $\mathrm{CO}_{2}$ stabilization target given certain technology costs and availabilities as outlined for light-duty vehicles in Table 1 and in the text below.

Figure 3. Global light-duty passenger vehicle fleet (millions) and primary energy supply for vehicle technology cost case \#1 and consistent for scenarios without a $\mathrm{CO}_{2}$ constraint (top panels), with $\mathrm{CO}_{2}$ stabilization at $500 \mathrm{ppm}$ (middle panels) and with $\mathrm{CO}_{2}$ stabilization at $450 \mathrm{ppm}$ (bottom panels). Neither carbon capture and storage (CCS) nor concentrating solar power (CSP) were available in these scenarios.
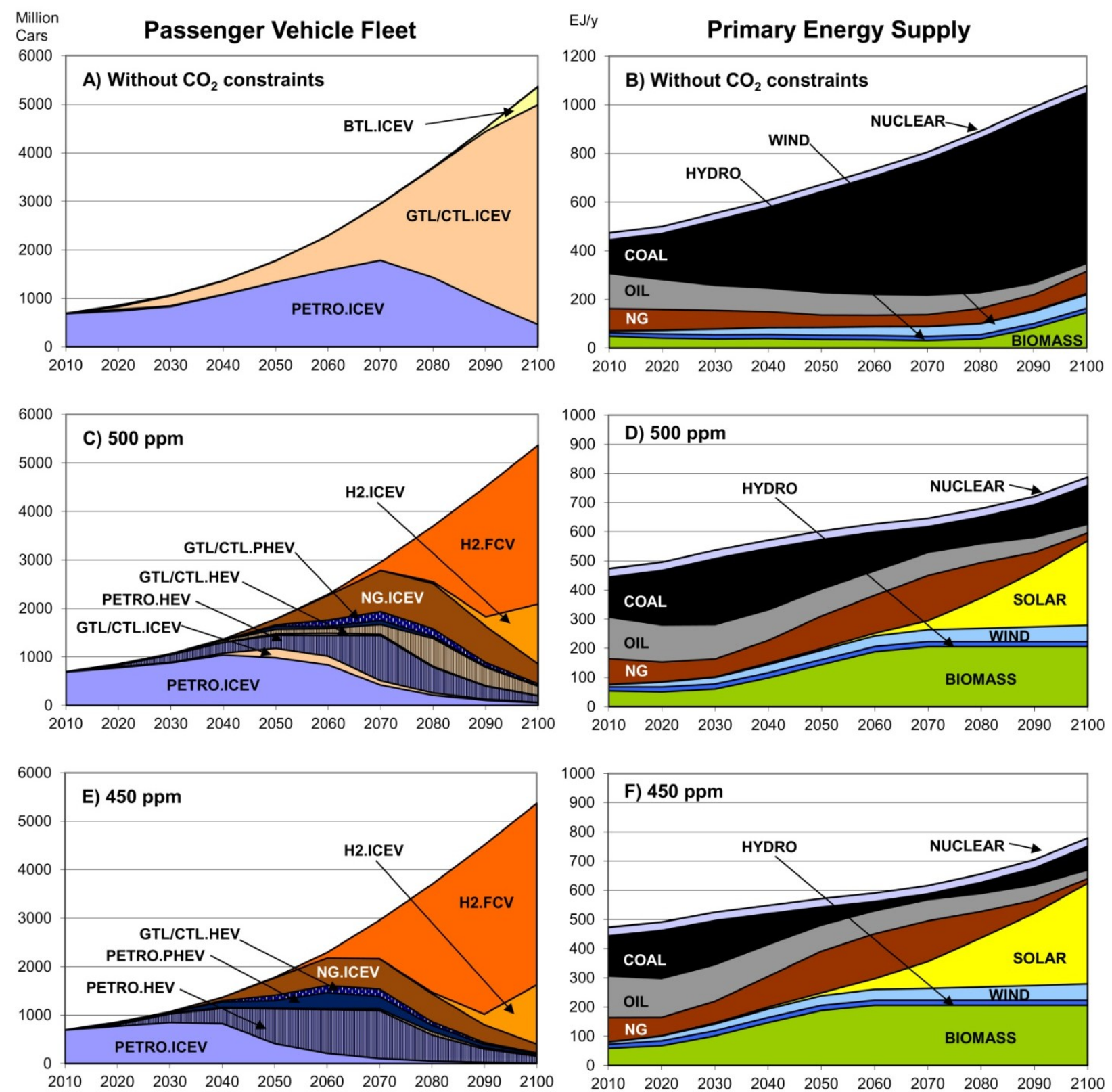
Figure 4. Global light-duty passenger vehicle fleet (millions) for vehicle technology cost cases \#2-7, consistent with $\mathrm{CO}_{2}$ stabilization at $450 \mathrm{ppm}$ for cases in which the hydrogen storage cost was assumed to be either $\$ 500, \$ 1,000, \$ 1,500, \$ 2,500, \$ 3,500$, or $\$ 4,500 / \mathrm{GJ}$. See text for further details. Neither CCS nor CSP were available in these scenarios.
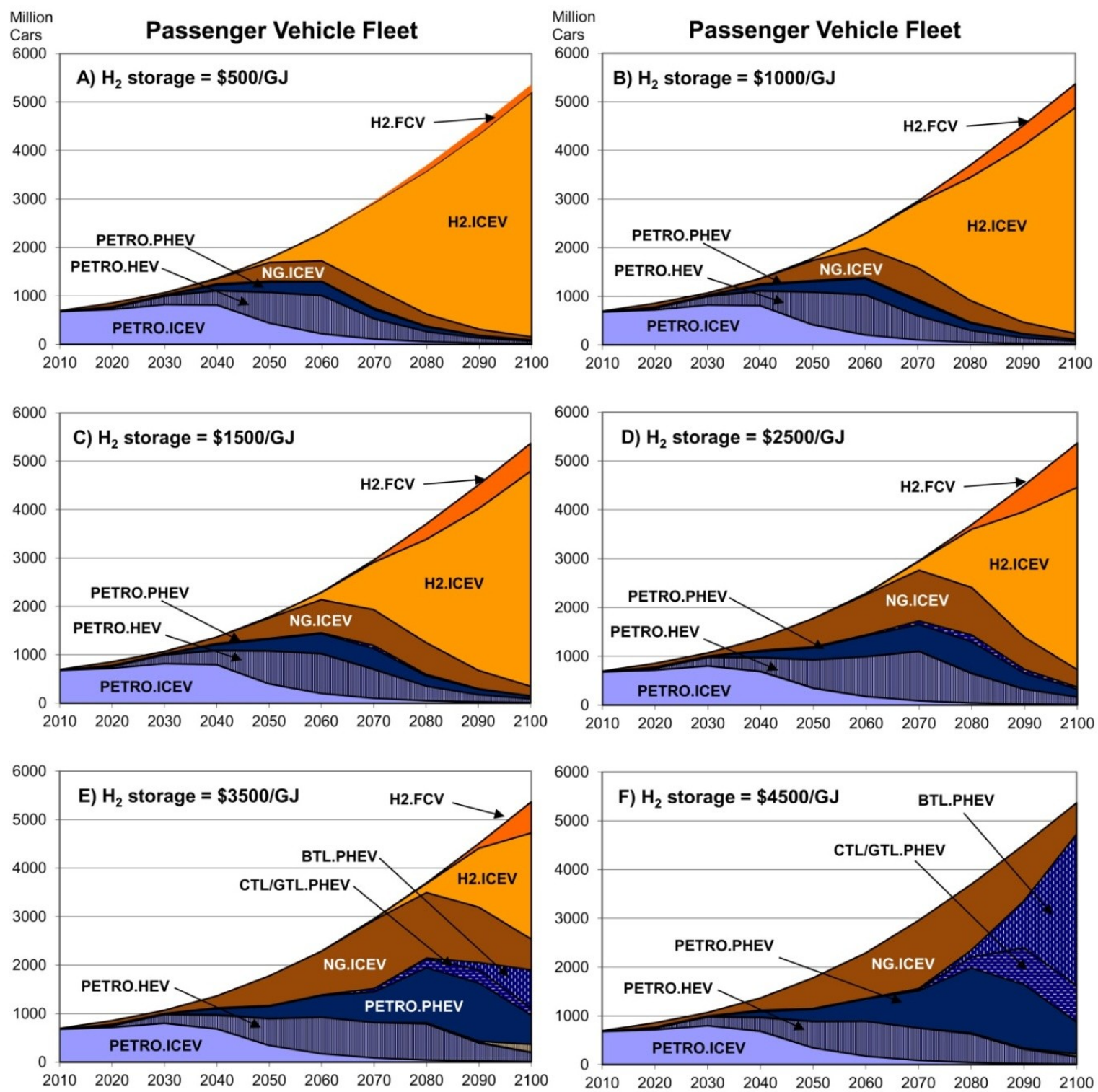

The left hand panels in Figure 3 show the global light-duty vehicle fleet over the time period 2010 to 2100. As discussed above, the demand for transportation by light-duty vehicles is assumed to be inelastic, and hence, the total vehicle fleet is the same in each of the cases investigated. The different segments of the light-duty vehicle fleet show the global contribution from the different vehicle-fuel technologies. The right hand panels in Figure 3 show the total global primary energy used over the time period 2010 to 2100 . Note that the primary energy supply figures are expressed in direct equivalents. While the demand for transportation, electricity, and heat is inelastic, the energy conversion pathways (with their differing associated energy efficiencies) to provide these services vary from case to case. The top panels in Figure 3 show the lowest cost solution to providing the global demands for transportation, electricity, and heat without a $\mathrm{CO}_{2}$ constraint. The middle two panels in 
Figure 3 show the lowest cost solution with a $500 \mathrm{ppm} \mathrm{CO}_{2}$ constraint. The bottom two panels in Figure 3 show the lowest cost solution with a $450 \mathrm{ppm} \mathrm{CO}_{2}$ constraint. As shown in the top right hand panel for Figure 3, in the absence of any $\mathrm{CO}_{2}$ constraint, the model selects to use large amounts of coal because it is inexpensive. Since conversion efficiencies are rather low for coal-based fuels and no advanced efficient vehicle technologies are used, the total primary energy used is higher in the case without a $\mathrm{CO}_{2}$ constraint than in the cases with a $\mathrm{CO}_{2}$ constraint.

Figure 5. Global light-duty passenger vehicle fleet (millions) for vehicle technology cost cases $\# 1,8,9,10$ consistent with $\mathrm{CO}_{2}$ stabilization at $450 \mathrm{ppm}$ for cases in which the hydrogen fuel cell stack cost was assumed to be either $\$ 45, \$ 65, \$ 95$, or $\$ 125 / \mathrm{kW}$. Neither CCS nor CSP were available in these scenarios.
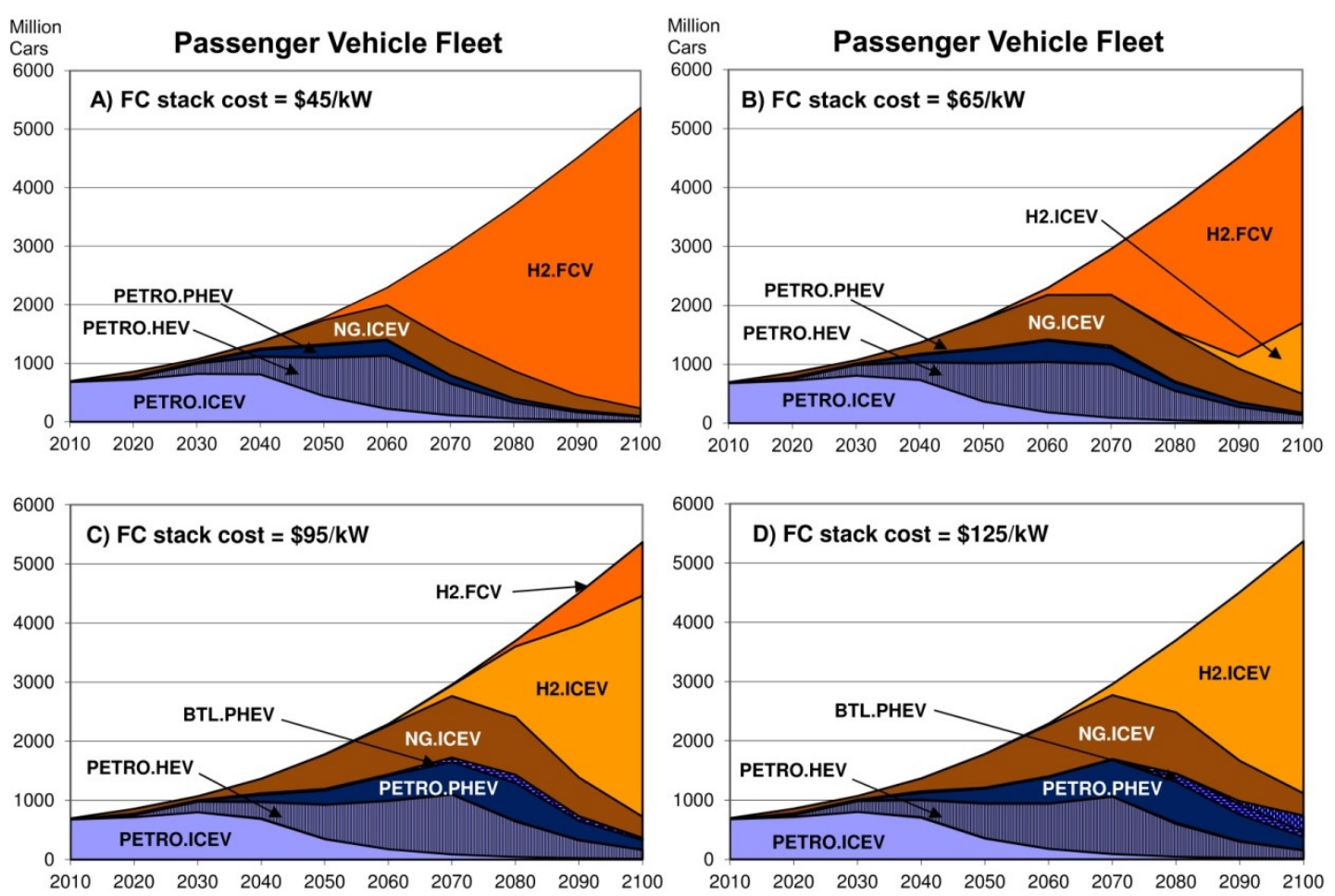

Figure 6. Global light-duty passenger vehicle fleet (millions) for vehicle technology cost cases \#4, 11 consistent with $\mathrm{CO}_{2}$ stabilization at $450 \mathrm{ppm}$ for cases in which the battery cost was assumed to be either $\$ 150$ or $\$ 300$. Neither CCS nor CSP were available in these scenarios.
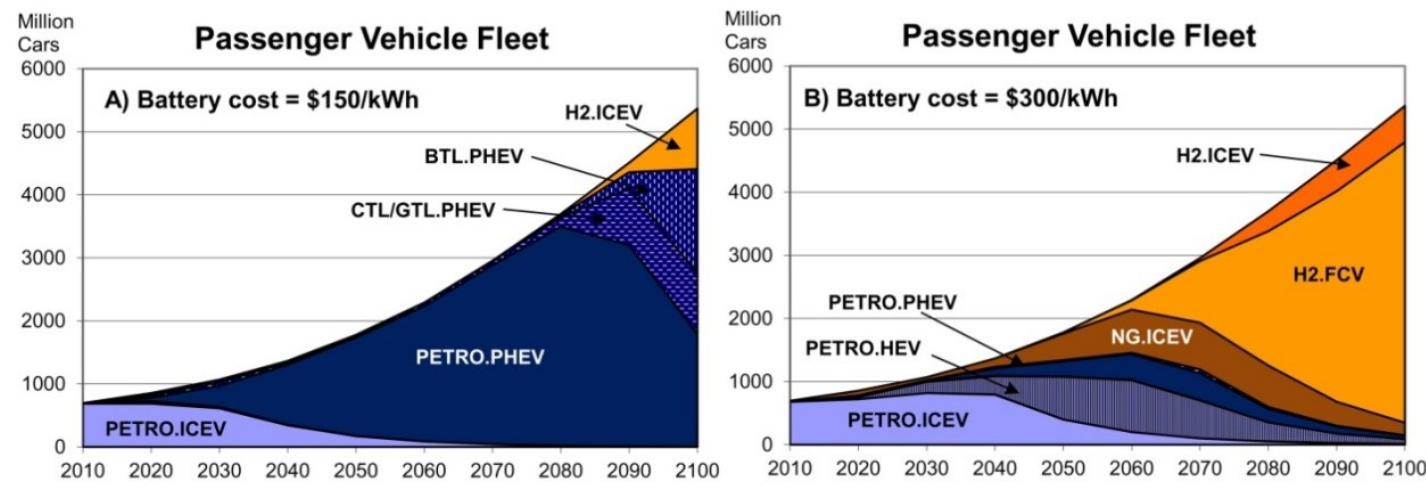
We reiterate the caveats mentioned above. The model is not designed to forecast the future development of the global energy system. The results are not predictions of the future light-duty vehicle fleet. However, we believe that the results described provide useful insights into the system dynamics which are likely to be present in a future carbon-constrained world and which can be used to inform decision makers.

\section{1. $\mathrm{CO}_{2}$ Targets}

Figure 3 illustrates the impact of the $\mathrm{CO}_{2}$ constraint on the lowest-cost light-duty vehicle and fuel technologies and primary energy sources. CCS and CSP are not available in these runs. The top two panels show the lowest-cost solution when no $\mathrm{CO}_{2}$ constraint is applied. As seen from the top left hand panel in Figure 3, light-duty vehicles are run largely on petroleum-based products until about 2070 when the use of petroleum declines giving way to GTL and CTL fuel. In the absence of a $\mathrm{CO}_{2}$ constraint, the lowest-cost solution to providing the demanded mobility is to use conventional ICEVs powered by petroleum then GTL and CTL. The small yellow sliver in Figure 3 that appears at 2080-2100 reflects the use of biofuel, which following the depletion of oil and natural gas, becomes the most cost-effective option in parts of the world where fossil fuel availability is limited (e.g., in South America).

The middle two panels in Figure 3, show the result when a $500 \mathrm{ppm} \mathrm{CO}_{2}$ constraint is imposed. The bottom two panels show the result for a $450 \mathrm{ppm}$ constraint. As the severity of the $\mathrm{CO}_{2}$ constraint is increased from $500 \mathrm{ppm}$ to $450 \mathrm{ppm}$, conventional petroleum ICEVs are replaced a few decades earlier by more efficient petroleum based HEVs.

Our finding that petroleum-fueled ICEV technology dominates for at least the 2010-2050 period for a 500 ppm stabilization target (see middle left hand panel in Figure 3) is consistent with results from Azar et al. [9] and Turton and Barreto [16]. Takeshita and Yamaji [32] ran a linear cost-minimizing energy model with a $\mathrm{CO}_{2}$ stabilization target of $550 \mathrm{ppm}$ by the year 2100 and with a business as usual scenario. For the 550 ppm scenario, they reported substantial (approximately $25 \%$ in 2100 ) use of BTL technology, while CTL/GTL was dominant for business as usual in 2100 . These results are broadly consistent with our findings. Gül et al. [21] used a MARKAL-based energy systems model to analyze competing energy carriers for Western Europe's transportation sector. In their $\mathrm{CO}_{2}$ reduction scenario (reduction from 1990 of $50 \%$ by 2050 and $75 \%$ by 2100), the car sector is dominated by gasoline/diesel (first in ICEVs, then HEVs and to a small extent also PHEVs) with hydrogen-fueled FCVs becoming dominant by 2100 . These are consistent with our findings (see Figure 3 ) in which petroleum-fueled ICEVs dominate initially and are replaced first by HEVs/PHEVs and then by hydrogen-fueled vehicles (ICEVs or FCVs).

\subsection{Vehicle Technology Costs}

Figures 4-6 illustrate the impact of assumptions regarding future hydrogen storage, fuel cell stack, and battery costs, respectively. In all cases, we show the composition of the global light duty vehicle fleet from 2010-2100 for the lowest cost solution that meets a 450 ppm $\mathrm{CO}_{2}$ stabilization target. In the following sections, we illustrate the sensitivity of the model results to cost assumptions for various 
vehicle components. It should be noted that in each of these illustrations the costs of other vehicle components are held fixed.

\subsubsection{Hydrogen Storage Cost}

Figure 4 shows the results using vehicle cost cases \#2-7 (see Table 1) in which the hydrogen storage cost was varied over the range $\$ 500-\$ 4,500 /$ GJ with all other parameters held constant (fuel cell stack cost $=\$ 95 / \mathrm{kW}$, battery cost $=\$ 300 / \mathrm{kWh}$, natural gas storage cost $=\$ 1,150 / \mathrm{GJ}$, and neither CCS nor CSP available). It might be perceived as odd that we examine the effect of variation of hydrogen storage costs over a wide range but retain a single fixed natural gas storage cost. If the same technology were chosen to store both gases then it would be inappropriate to assume a fixed cost to store natural gas but a wide range of costs to store hydrogen. By comparing results from cases \#2-7 we implicitly assume that different technologies are used to store the two gases.

As illustrated in the bottom right hand panel $\mathrm{F}$ of Figure 4, at the highest hydrogen storage cost considered (\$4,500/GJ, case \#7), hydrogen fueled vehicles were not part of the lowest cost solution. Instead, the model chooses to replace conventional petroleum fueled ICEVs over the period 2030-2060 with electrified vehicles (HEVs and PHEVs) fueled with petroleum. Natural gas powered ICEVs are also selected in substantial volumes. In approximately 2070, PHEVs fueled by CTL, GTL, and BTL begin to enter the fleet in large numbers and become dominant by approximately 2100 (see panel F). As shown in panel $\mathrm{E}$ in Figure 4, when the hydrogen storage cost is lowered to $\$ 3,500 / \mathrm{GJ}$ hydrogen, ICEVs appear (albeit in relatively modest volumes at the end of the century) in the lowest cost solution. Progressing through panels D to A in Figure 4, it can be seen that further lowering the cost of hydrogen storage results in progressively earlier introduction and increased volumes of hydrogen powered ICEVs in the global fleet.

\subsubsection{Hydrogen Fuel Cell Stack Cost}

Figure 5 shows the results obtained using vehicle cost cases \#1, 8-10 (see Table 1) in which the fuel cell stack cost was varied over the range $\$ 45-\$ 125 / \mathrm{kW}$ with all other parameters held constant (hydrogen storage fuel cell stack cost $=\$ 2,500 / \mathrm{GJ}$, battery cost $=\$ 300 / \mathrm{kWh}$, natural gas storage $\operatorname{cost}=\$ 1,150 / \mathrm{GJ}$, and neither CCS nor CSP available). Figure 5 illustrates the impact of assumptions regarding the fuel cell stack cost on the lowest cost vehicle/fuel technology choices in meeting a $450 \mathrm{ppm} \mathrm{CO}_{2}$ stabilization target in the absence of either CCS or CSP. As illustrated in the bottom two panels $\mathrm{C}$ and $\mathrm{D}$ in Figure 5, hydrogen fuel cell vehicles (H2 FCVs) are not cost competitive with hydrogen internal combustion engine vehicles (H2 ICEVs) for fuel cell stack costs $\geq \$ 95 / \mathrm{kW}$, and hence, hydrogen fuel cell vehicles are not selected by the model in these scenarios. Comparing panels $\mathrm{B}$ and $\mathrm{C}$, it can be seen that fuel cell vehicles become competitive when the fuel cell stack cost is $\$ 65 / \mathrm{kW}$. Lowering the fuel cell stack cost further to $\$ 45 / \mathrm{kW}$ results in H2 ICEVs being uncompetitive, and the model selects large volumes of H2FCVs beyond approximately 2050 (see panel A).

\subsubsection{Battery Cost}

Figure 6 shows the results obtained using vehicle cost cases \#4 and 11 (see Table 1) in which the battery cost was set at either $\$ 150$ or $\$ 300 / \mathrm{kWh}$ with all other parameters held constant (hydrogen 
storage cost $=\$ 1,500 / \mathrm{GJ}$, fuel cell stack $=\$ 95 / \mathrm{kW}$, natural gas storage cost $=\$ 1,150 / \mathrm{GJ}$, and neither CCS nor CSP available). With decreased battery price, and hence decreased vehicle cost, PHEVs become more attractive. With a battery cost of $\$ 300 / \mathrm{kWh}$, PHEVs do not make a major contribution to the lowest-cost result. The left panel in Figure 6 shows that PHEVs become a dominating cost-effective solution for battery costs at the low end of the range investigated $(\$ 150 / \mathrm{kWh})$.

\subsection{CCS and CSP Availability}

The availability of CCS and CSP can have a profound influence on the lowest-cost passenger vehicle fuel and technology choice in a carbon-constrained world. Figure 7 shows the results for vehicle cost case \#12 with three combinations of CCS and CSP availability. The top two panels in Figure 7 show the lowest cost solution when neither CCS, nor CSP, is available. The middle two panels in Figure 7 show the lowest cost solution when CCS is available but CSP is not available. Finally, the bottom two panels in Figure 7 show the lowest cost solution when both CCS and CSP are available.

The availability of CCS (compare middle two panels with top panels in Figure 7) extends the use of conventional petroleum-fueled ICEVs by a few decades, results in the use of some ICEVs and HEVs fueled by biofuels and CTL/GTL, and delays the introduction of hydrogen (produced from coal with CCS). As seen by comparing the top and middle right hand panels, when CCS is made available, the model chooses to greatly increase the use of coal (with CCS) at the expense mainly of solar photovoltaic (PV). The model also chooses to employ CCS with biomass. The mechanism at work is that $\mathrm{CCS}$ provides relatively inexpensive low- $\mathrm{CO}_{2}$ electricity and heat from coal, which prolongs the use of traditional ICEVs. The availability of CCS leads to coal displacing biomass (biomass is a limited resource that is scarce in the carbon constrained scenarios) in the heat sector, allowing increased production of transportation fuel from biomass (when CCS is not available, biomass is used mostly to provide heat). While CCS enables the production of much cheaper hydrogen (from coal instead of solar), the overall importance of hydrogen decreases reflecting the fact that CCS enables non-transport sectors to realize more emission reductions at a lower cost than in the transport sector.

When CSP is also made available (see bottom two panels in Figure 7), CSP-generated electricity (see bottom right hand panel in Figure 7) is used in the global energy system (although not in transportation), which displaces the small amount of solar-hydrogen in the middle right hand panel in Figure 7. This makes biomass, which would otherwise go to the stationary sectors, available for conversion into biofuel for vehicles that ultimately displace hydrogen (see increased biofuel [BTL] and decreased hydrogen sections in bottom left hand compared to middle left hand panel in Figure 7). 
Figure 7. Global light-duty passenger vehicle fleet (millions) and primary energy supply for case \#12 vehicle technology costs and consistent with $\mathrm{CO}_{2}$ stabilization at $450 \mathrm{ppm}$ for scenarios in which neither carbon capture and storage nor concentrating solar power are available (top panels), where carbon capture and storage is available but concentrating solar power is not available (middle panels), and where both carbon capture and storage and concentrating solar power are available (bottom two panels).
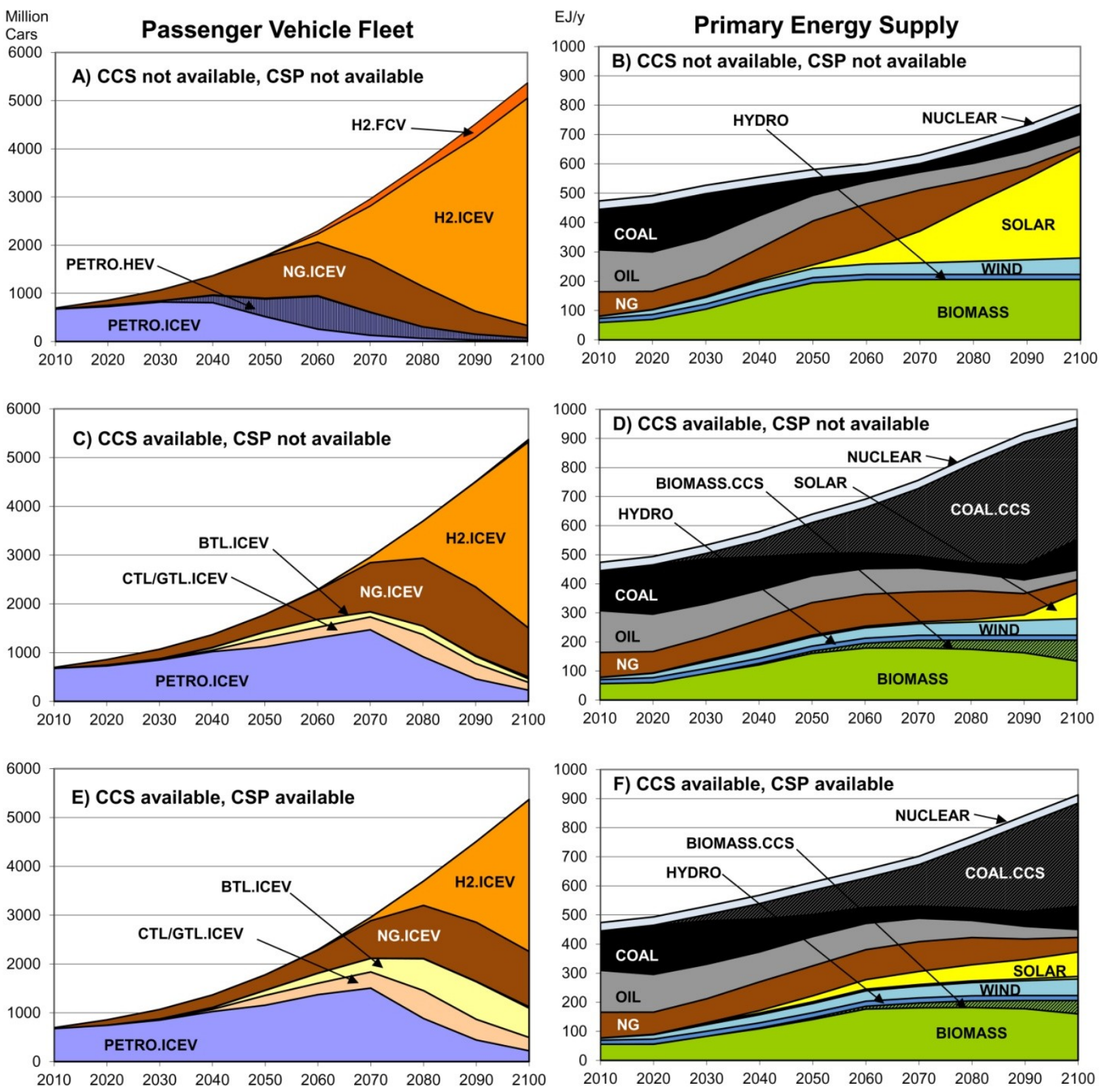

\section{Conclusions}

Planning a sustainable mobility strategy is a complex undertaking. Economic, social, and environmental pillars of sustainability need to be addressed and within each pillar several elements need consideration. The impact on climate change is a key factor in environmental sustainability. The development of a strategy that addresses climate change is challenging because of the multitude of different vehicle and fuel technology combinations that are available in the transport sector, the 
uncertainties in the future costs of advanced vehicle technologies, and the importance of connections between the different energy sectors.

The global energy model used here has been developed in several steps. The original model was presented in 2003 [9], it was later regionalized [10,11] and then expanded with a more detailed transportation sector [12] as a tool to aid decision makers in the development of sustainable personal mobility. We present results from the model that illustrate two major findings. First, there is no identifiable "silver bullet" vehicle or fuel technology for sustainable mobility. As illustrated in Figures 4-6, varying the costs of future vehicle technology over ranges that we believe to be reasonable (taken from government and industry research and development targets) leads to large differences in the resulting lowest cost solutions. It is too early to pick winners, and the prudent approach is to follow a portfolio strategy with research and development of multiple fuel and vehicle technology pathways. Second, in a carbon constrained world, recognizing and accounting for the connections between the energy sectors is important, and the strategy needs to be robust to developments in the other energy sectors. In all scenarios considered in our present and previous [11-13] work there is no single vehicle or fuel technology which dominates throughout the century and typically several vehicle-fuel technology combinations contribute significantly. The diversity of technology combinations in Figures 1-5 highlights the need for research and development of multiple technologies.

The practical ramifications of this analysis are illustrated in the portfolio approach to providing sustainable mobility adopted by the Ford Motor Company. Ford offers an all-electric vehicle, plug-in hybrid electric vehicles, hybrid electric vehicles, and 17 flexible-fuel vehicle models across global platforms. Ford produces vehicles that can be converted to run on compressed natural gas (CNG) and liquefied petroleum gas (LPG) and is continuing laboratory-based research and development of technologies necessary to commercialize hydrogen fuel cell vehicles. Ford's portfolio strategy is informed by analyses such as that presented above and provides customers with a variety of vehicle choices with sustainable technologies and alternative fuel options to meet their driving needs [33].

\section{Acknowledgments}

We thank C. Azar and K. Lindgren for help and guidance in developing the model and Jim Anderson, John Ginder, Mike Tamor, Mike Veenstra, Sandy Winkler for helpful discussions. We thank Sandy Winkler for providing Figure 1. Financial support from Swedish Agency for Innovation Systems, Vinnova, and Swedish Energy Agency, when developing different versions of the GET model, is gratefully acknowledged.

\section{References and Notes}

1. IPCC. Climate Change 2007: The Physical Science Basis; Cambridge University Press: Cambridge, UK, 2007.

2. United Nations Framework Convention on Climate Change (UNFCCC). Available online: http://unfccc.int/essential_background/convention/background/items/1353.php/ (accessed on 24 September 2010). 
3. Rogelj, J.; Hare, W.; Lowe, J.; van Vuuren, D.P.; Riahi, K.; Matthews, B.; Hanaoka, T.; Jiang, K.; Meinshausen, M. Emission pathways consistent with a $2{ }^{\circ} \mathrm{C}$ global temperature limit. Nat. Clim. Change 2011, 1, 413-418.

4. Wigley, T.M.L.; Richels, R.; Edmonds, J.A. Economic and environmental choices in the stabilization of atmospheric $\mathrm{CO}_{2}$ concentrations. Nature 1996, 379, 240-243.

5. Wallington, T.J.; Anderson, J.E.; Winkler, S.L.; Grahn, M. Sustainable mobility: Insights from a global energy model. In Treatise on Sustainability Science and Engineering; Springer: New York, NY, USA, 2013.

6. World Business Council for Sustainable Development. Mobility 2030: Meeting the Challenges to Sustainability; WBCSD: Geneva, Switzerland, 2004; ISBN: 2-940240-57-4.

7. Friedlingstein, P.; Houghton, R.A.; Marland, G.; Hackler, J.; Boden, T.A.; Conway, T.J.; Canadell, J.G.; Raupach, M.R.; Ciais, P.; Le Quéré, C. Update on $\mathrm{CO}_{2}$ emissions. Nat. Geosci. 2010, 3, 811-812.

8. Azar, C.; Lindgren, K.; Andersson, B.A. Hydrogen or methanol in the transportation sector? In KFB-Report 2000:35, ISBN: 91-88371-90-5; Swedish Agency for Innovation Systems (VINNOVA): Stockholm, Sweden, 2000.

9. Azar, C.; Lindgren, K.; Andersson, B.A. Global energy scenarios meeting stringent $\mathrm{CO}_{2}$ constraints-Cost effective fuel choices in the transportation sector. Energy Policy 2003, 31, 961-976.

10. Azar, C.; Lindgren, K.; Larson, E.; Mollersten, K. Carbon capture and storage from fossil fuels and biomass - Costs and potential role in stabilizing the atmosphere. Clim. Change 2006, 74, 47-79.

11. Grahn, M.; Azar, C.; Lindgren, K. The role of biofuels for transportation in $\mathrm{CO}_{2}$ emission reduction scenarios with a global versus a regional carbon cap. Biomass Bioenerg. 2009, 33, 360-371.

12. Grahn, M.; Azar, C.; Williander, M.I.; Anderson, J.E.; Mueller, S.A.; Wallington, T.J. Fuel and vehicle technology choices for passenger vehicles in achieving stringent $\mathrm{CO}_{2}$ targets: Connections between transportation and other energy sectors. Environ. Sci. Technol. 2009, 43, 3365-3371.

13. Wallington, T.J.; Grahn, M.; Anderson, J.E.; Mueller, S.A.; Williander, M.I.; Lindgren, K. Low- $\mathrm{CO}_{2}$ electricity and hydrogen: A help or hindrance for electric and hydrogen vehicles? Environ. Sci. Technol. 2010, 44, 2702-2708.

14. Endo, E. Market penetration analysis of fuel cell vehicles in Japan by using the energy system model MARKAL. Int. J. Hydrog. Energy 2007, 32, 1347-1354.

15. Turton, H.; Barreto, L. Automobile technology, hydrogen and climate change: A long term modelling analysis. Int. J. Altern. Propulsion 2007, 1, 397-426.

16. Gül, T.; Kypreos, S.; Barreto, L. Hydrogen and Biofuels-A Modelling Analysis of Competing Energy Carriers for Western Europe; In Proceedings of the World Energy Congress "Energy Future in an Interdependent World", Rome, Italy, 11-15 November 2007.

17. Anandarajah, G.; McDowall, W.; Ekins, P. Decarbonising road transport with hydrogen and electricity: Long term global technology learning scenarios. Int. J. Hydrog. Energy 2013, 38, 3419-3432.

18. Girod, B.; van Vuuren, D.P.; Deetman, S. Global travel within the $2{ }^{\circ} \mathrm{C}$ climate target. Energy Policy 2012, 45, 152-166. 
19. Kyle, P.; Kim, S.H. Long-term implications of alternative light-duty vehicle technologies for global greenhouse gas emissions and primary energy demands. Energy Policy 2011, 39, 3012-3024.

20. Girod, B.; van Vuuren, D.P.; Grahn, M.; Kitous, A.; Kim, S.H.; Kyle, P. Climate impact of transportation: A model comparison. Clim. Change 2013, doi 10.1007/s10584-012-0663-6.

21. Hua, T.Q.; Ahluwalia, R.K.; Peng, J.K.; Kromer, M.; Lasher, S.; McKenney, K.; Law, K.; Sinha, J. Technical assessment of compressed hydrogen storage tank systems for automotive applications. Int. J. Hydrog. Energy 2011, 36, 3037-3049.

22. Ahluwalia, R.K.; Wang, X. Fuel cell systems for transportation: Status and trends. J. Power Sources 2008, 177, 167-176.

23. Global Energy Perspectives; Nakicenovic, N., Grübler, A., McDonald, A., Eds.; IIASA/WEC, Cambridge University Press: London, UK, 1998; p. 317.

24. Johansson, T.B.; Kelly, H.; Reddy, A.K.N.; Williams, R.H. Renewable Energy-Sources for Fuels and Electricity; Burnham, L., Ed.; Island Press: Washington, DC, USA, 1993.

25. Doornbosch, R.; Steenblik, R. Round Table on Sustainable Development. In Biofuels: Is the Cure Worse Than the Disease? Report No. SG/SD/RT(2007)3/REV1; Organisation for Economic Co-operation and Development: Paris, France, 2007; Available online: http://www.oecd.org/ dataoecd/9/3/39411732.pdf (accessed on 12 March 2012).

26. Hoogwijk, M. On the Global and Regional Potential of Renewable Energy Sources, Ph.D. Thesis, Utrecht University, Utrecht, The Netherlands, 2004.

27. British Petroleum, Statistical Guide of World Energy 2008. Available online: http://www.bp.com/ (accessed on 2 September 2009).

28. Swedish EPA. Excel Document: Emissionsfaktorer Växthusgaser och Luftföroreningar från Förbränning. Available online: http://www.naturvardsverket.se/ (accessed on 27 January 2013).

29. IPCC. Special report on carbon dioxide capture and storage. In Prepared by Working Group III of the Intergovernmental Panel on Climate Change; Metz, B., Davidson, O., de Coninck, H.C., Loos, M., Meyer, L.A., Eds.; Cambridge University Press: Cambridge, UK, New York, NY, USA, 2005; p. 442.

30. Grahn, M.; Anderson, J.E.; Wallington, T.J. Cost-Effective Vehicle and Fuel Technology Choices in a Carbon Constrained World: Insights from Global Energy Systems Modeling. In A Survey of Alternative Vehicles and Their Power Sources; Elsevier: New York, NY, USA, 2010.

31. U.S. Advanced Battery Consortium. Available online: http://www.uscar.org/ (accessed on 1 March 2008).

32. Takeshita, T.; Yamaji, K. Important roles of Fischer-Tropsch synfuels in the global energy future. Energy Policy 2008, 36, 2791-2802.

33. Ford Motor Company, Sustainability 2011/12. A Portfolio Approach. Available online: http:// corporate.ford.com/microsites/sustainability-report-2011-12/environment-products-plan-portfolio/ (accessed on 4 April 2013).

(C) 2013 by the authors; licensee MDPI, Basel, Switzerland. This article is an open access article distributed under the terms and conditions of the Creative Commons Attribution license (http://creativecommons.org/licenses/by/3.0/). 